\title{
Correction to: Response (minimum clinically relevant change) in ASD symptoms after an intervention according to CARS-2: consensus from an expert elicitation procedure
}

\author{
Lucie Jurek $^{1}$ (1) $\cdot$ Matias Baltazar $^{1} \cdot$ Sheffali Gulati $^{2} \cdot$ Neda Novakovic $^{3} \cdot$ María Núñez $^{4} \cdot$ Jeremy Oakley $^{5}$. \\ Anthony O'Hagan ${ }^{5}$
}

Published online: 28 August 2021

(c) Springer-Verlag GmbH Germany, part of Springer Nature 2021

\section{Correction to: European Child \& Adolescent Psychiatry https://doi.org/10.1007/s00787-021-01772-z}

In the original article, the second author name was published incorrectly. The correct name is Matias Baltazar.

The original article has been corrected.

The original article can be found online at https://doi.org/10.1007/ s00787-021-01772-z.

Lucie Jurek

lucie.jurek@ch-le-vinatier.fr

1 Child and Adolescent Psychiatry Department, Center for Assessment and Diagnostic of Autism, Le Vinatier Hospital, Bron, France

2 Centre of Excellence and Advanced Research on Childhood Neurodevelopmental Disorders, Child Neurology Division, Department of Pediatrics, All India Institute of Medical Sciences, New Delhi, India

3 Day Care Centre for Children and Adolescents with Developmental Disabilities, Belgade, Serbia

4 Faculty of Psychology, Universidad Autónoma de Madrid, Campus de Cantoblanco, Madrid, Spain

5 School of Mathematics and Statistics, The University of Sheffield, Hounsfield Road, Sheffield, UK 